\title{
29. POLLEN ANALYSIS OF SITE 436 CORES, LEG 56, DEEP SEA DRILLING PROJECT
}

\author{
Seiji Sato, Department of Geology and Mineralogy, Hokkaido University, Sapporo, Japan
}

\section{INTRODUCTION}

Pollen analysis of core samples from Site 436 located at the crest of the trench swell east of the Japan Trench, off Miyako, northern Honshu, Japan, was carried out in order to obtain information concerning not only the climatic and marine conditions but also the plate motion. The results show that the pollen-rich zone, pollenrare zone, and pollen-barren zone were stratigraphically discriminated. The significance of the results is discussed.

\section{PREPARATION OF MATERIAL}

The material for the present study was prepared by the following procedures. Sediment was (1) boiled in 10 per cent potassium hydroxide solution for 40 to 90 minutes and washed with water; (2) soaked in hydrofluoric acid for 2 to 12 hours and then washed with water; (3) heated in the mixed solution of nitric acid, hydrochloric acid, and water $\left(1: 1: 1\right.$ in volume) at $60^{\circ} \mathrm{C}$ for 5 minutes and then washed with water; (4) slides were prepared. Procedures (3) and (4) were repeated two to three times.

\section{RESULTS}

The results of the pollen analysis are shown in Figure 1 , which represents the frequency of pollen and spores in percentage. In each sample 150 to 200 pollen grains, excluding microplanktons, spores, and Sporomorph A, were counted under the microscope. The frequencies of microplanktons, spores (noted as Ts and Ms in Figure 1), and Sporomorph A, accompanied by pollen grains, are shown in percentage for the 150 to 200 grains. Because Sporomorph A often occurs so abundantly, I have modified the scale of the diagram of the species accordingly. Microplanktons and Sporomorph A may be regarded as marine elements.

\section{DISCUSSION AND CONCLUSIONS}

The composition of the pollen assemblage in ocean floor sediments is influenced by many factors, such as the vegetation from which the pollen and spores derive - which of course reflects climatic conditions - and the ocean currents and winds by which pollen and spores were transported. However, it is impossible at present to determine the predominant factor in the composition of the Hole 436 pollen assemblage.

The significance of the results is summarized as follows:

(1) The environment in which the sediments of Hole 436 accumulated has not been constant over time. This is inferred from the fluctuation of the occurrence of microplanktons and Sporomorph A.

(2) Although abundant pine (Pinus) pollen in marine sediments has been reported by many authors (Koreneva, 1966; Traverse and Ginsburg, 1966; Cross et al., 1966 , among others), the present data show that it is not always the case.

(3) The arrangement of the barren zone, pollenscarce zone, and pollen-rich zone in that order from the bottom of the Hole is not inconsistent with the theory of plate tectonics. That is to say, if the Pacific Plate has moved westward from mid latitudes toward the Japanese Islands, the sediments on the plate should contain more pollen and spores derived from the land. The fact noted in (1) may also indicate this plate motion.

(4) There was no clear change in the pollen assemblage at the boundary between the Pliocene and Pleistocene sequence.

Because the composition of the pollen assemblage in marine sediments is greatly influenced by the water currents which transport the pollen and spores, it should change if the pattern of currents changes. On the other hand, if the Pacific Plate moves, the pollen assemblage on the sea floor should also change, even if the pattern of the currents remains constant. Once the history of fluctuations in the transportation factors is understood, these data may warrant a more detailed reinterpretation.

\section{REFERENCES}

Cross, A. T., Thompson, G. G., and Zaitzeff, J. B., 1966. Source and distribution of palynomorphs in bottom sediments, southern part of Gulf of California. Mar. Geol., 4, 467-524.

Koreneva, E. V., 1966. Marine palynological researches in the U.S.S.R. Mar. Geol., 4, 563-574.

Traverse, A., and Ginsburg, R. N., 1966. Palynology of the surface sediments of Great Bahama Bank, as related to water movement and sedimentation. Mar. Geol., 4, 417459. 
GROUP A

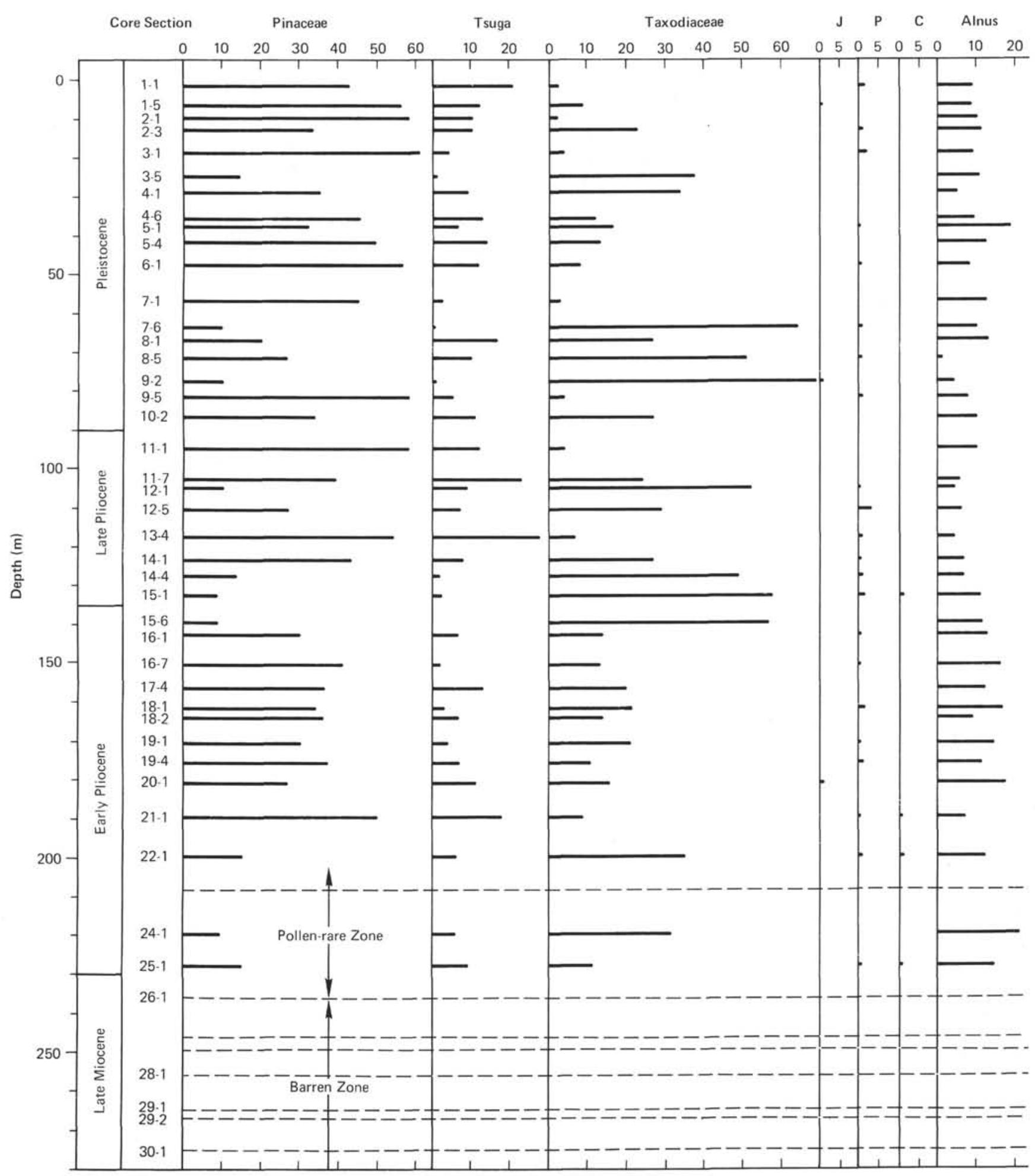

Figure 1. Pollen diagram of Hole 436 sediments. The age assignment is based on diatoms, radiolarians, and other fossils. Group A pollen types are shown as relative per cent of the total pollen assemblage (counts of 150-200 pollen grains). Group B (microplanktons, spores, and Sporomorph A) are shown as percentage abundance relative to pollen; thus percentage can exceed 100. Key: J: Juglans. P: Pterocarya. C: Carya. B: Betula. Ca: Carpinus. Co: Corylus. Tpo: Triporate pollen, genus indeterminable. F: Fagus. Q: Quercus. Tcl: Tricolpate pollen, genus indeterminable. U\& Z: Ulmus and Zelkova. Ch: Chenopodiaceae. Microplanktons: mainly dinoflagellata and acritarchs. Ts: Trilete spores. Ms: Monolete spores. Sporomorph A: Spherical, less than $10 \mu \mathrm{m}$ in diameter, surface smooth, biological affinity unknown, not found in terrestrial sediments. 
GROUP B

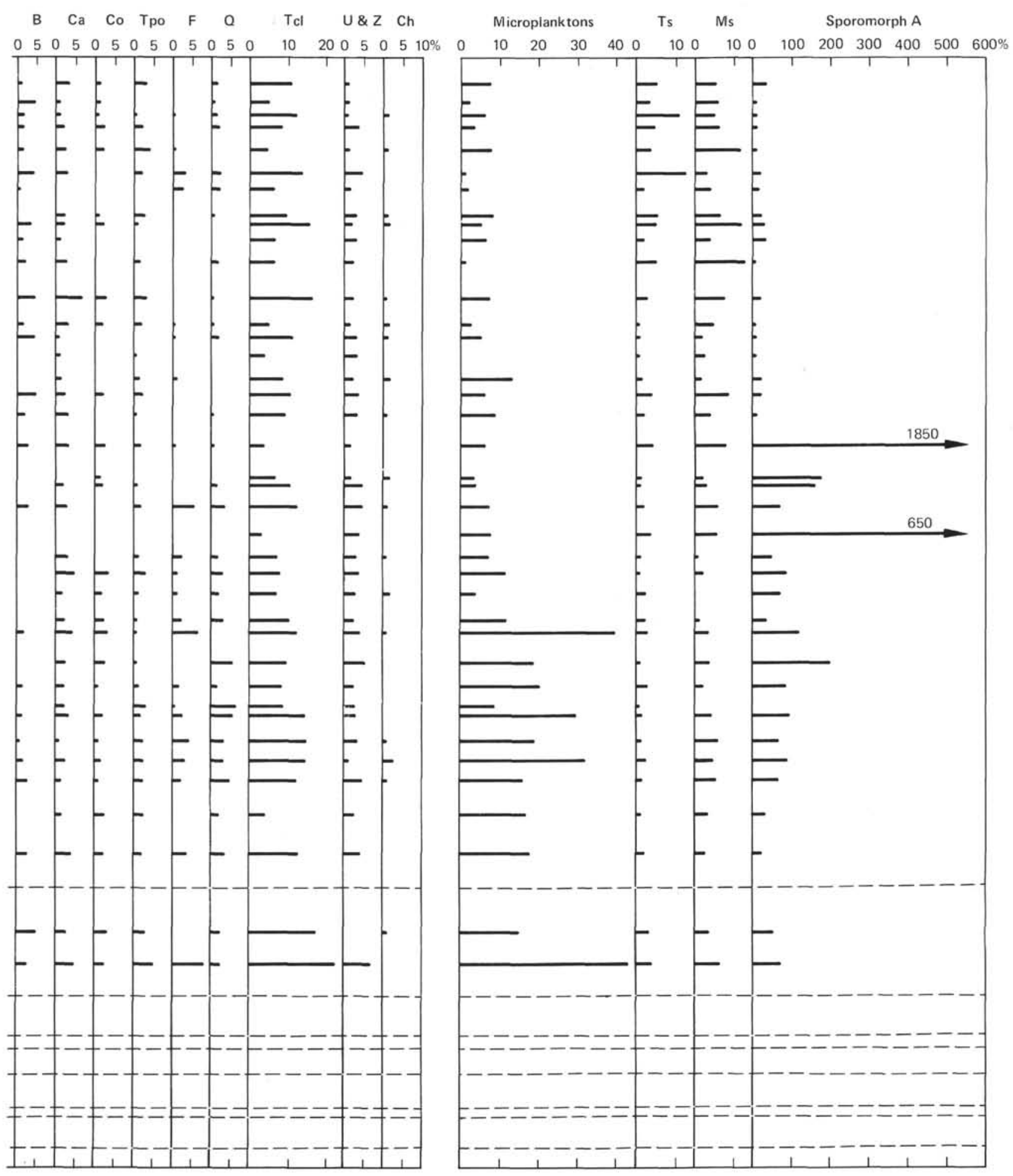

Figure 1. (Continued). 